\title{
A 12-Month Lifestyle Intervention Program Improves Body Composition and Reduces the Prevalence of Prediabetes in Obese Patients
}

\author{
Daniel König $^{a}$ Jenny Hörmann ${ }^{b}$ Hans-Georg Predel ${ }^{c} \quad$ Aloys Berg $^{d}$ \\ a Institute for Sports and Sports Science, University of Freiburg, Freiburg i.Br., Germany; \\ ${ }^{b}$ M.O.B.I.L.I.S. e.V., Freiburg i.Br., Germany; ${ }^{C}$ Institute of Cardiology and Sports Medicine, \\ German Sport University Cologne, Cologne, Germany; d Medical Faculty, University of \\ Freiburg, Freiburg i.Br., Germany
}

\section{Keywords}

Lifestyle intervention · Prediabetes · Diabetes prevention

\begin{abstract}
Background: The present study investigated the effects of a 12-month interdisciplinary standardized lifestyle program addressing physical activity and changes in dietary and lifestyle behavior in 2,227 obese prediabetic participants. Methods: Measures of obesity (BMI, waist circumference), cardiopulmonary fitness, and metabolic parameters were determined before and after the intervention period. Results: From the 2,227 participants who were initially prediabetic, 839 participants $(-37.7 \%)$ did no longer show the criteria of prediabetes after the intervention and had normal HbA1c levels. Conclusion: The clinical effects are substantial, and it is likely that the applied intense and multidisciplinary lifestyle interventions could reduce the risk of developing diabetes and the prevalence of a full-blown metabolic syndrome in obese and prediabetic patients.

\section{Introduction}

Obesity is one of the major health burdens in Western societies. Particularly its impact on the prevalence of diabetes and subsequent cardiovascular disease has been demonstrated in numerous investigations [1]. In contrast, lifestyle intervention trials have shown that weight reduction in combination with increased physical activity improve glucose metabolism and metabolic risk factors [2,3]. In two large randomized studies, the Diabetes Prevention Project from Finland and the Diabetes Prevention Program (DPP) from the USA,

Prof. Dr. med. Aloys Berg

Medizinische Fakultät

Universität Freiburg

Hugstetter Straße 55, 79106 Freiburg, Germany

aloys.berg@klinikum.uni-freiburg.de 
König et al.: A 12-Month Lifestyle Intervention Program Improves Body Composition and Reduces the Prevalence of Prediabetes in Obese Patients

patients with prediabetes were randomized into a group with either intensive lifestyle intervention or metformin treatment or with usual care. Data from both studies revealed a significant reduction in the conversion rate of prediabetes to diabetes by $58 \%$ over a period of 4 years [2,3]. Furthermore, it has been shown that the risk to develop type 2 diabetes mellitus (T2DM) was significantly lower in those participants who had returned to normal glucose levels than in those who maintained in the prediabetic state; interestingly, the risk remained significantly reduced, even if the reversion to normal glucose levels was only transient [4].

Normalization of glucose metabolism and accompanied risk factors is crucial for risk reduction of cardiovascular disease. Therefore, current prevention guidelines encourage the implementation of lifestyle measures such as weight reduction and increased physical activity $[5,6]$.

However, data from large intervention trials investigating the effects of a standardized lifestyle intervention program in the general population are scarce. Therefore, we conducted a study implementing lifestyle changes (M.O.B.I.L.I.S. program) in moderately obese individuals and followed their weight and metabolic risk factors over a period of 12 months. In this analysis, we particularly focused on obese participants with prediabetes and the possible reconversion of prediabetes to normal glucose regulation by this standardized lifestyle program.

\section{Material and Methods}

Between 2004 and 2013 obese individuals ( $\mathrm{n}=5,884$; BMI 30-40 kg/m²; male $\mathrm{n}=1,510$; female $\mathrm{n}=$ 4,374) were enrolled in the M.O.B.I.L.I.S. program, which has been described previously [7, 8]. The program was offered in more than 100 German communities by a non-profit organization (M.O.B.I.L.I.S. e.V., Freiburg i.Br., Germany). Potential participants were addressed by advertisement or by their general practitioner to take part in this lifestyle program. The program consisted of 12 months of interdisciplinary group sessions addressing physical activity as well as changes in diet and lifestyle behavior in 61 sessions $(\mathrm{n}=41$ practical physical activity sessions; $\mathrm{n}=12$ psychological intervention/self-management; $\mathrm{n}=8$ nutritional counseling sessions). Participants had to pay for the courses and were partially reimbursed by their insurance company by $85 \%$ at the end of the program, when $80 \%$ of the sessions had been attended.

The dietary intervention was based on the concept of the glycemic index (GI) as well as on a reduction in energy-dense food by reducing dietary fat intake. One of the main tool for the participants was a traffic light system, which helped them to make the right decisions for energy-restricted and high-quality, low-GI food [7].

Particular attention was payed to the psychological self-management. The participants learnt to integrate their behavioral changes in their everyday lives. The topics in the behavioral changes were discussed with a psychologist in the group meetings; furthermore, the participants were encouraged to continue with specific tasks in their daily life related to behavioral modification and to document their progress. In this way, participants were taught cognitive-behavioral strategies of goal setting, action planning, barrier management, and self-monitoring $[9,10]$.

Subjects were eligible if they were over 18 years of age, had no contraindication to physical exercise and training, and were able to complete at least $75 \mathrm{~W}$ during a cycle ergometry. Exclusion criteria were type 1 diabetes, hepatic or renal diseases, psychiatric disorders including severe eating disorders such as binge eating disorder, obesity medication, bariatric surgery, and cancer (cancer-free survival of more than 5 years). Coronary heart disease was not an exclusion criterion. Prediabetes was defined according to the American Diabetes Association criteria as an HbA1c between 5.70 and 6.49\% [5].

Laboratory analysis included serum triglycerides, total cholesterol, HDL cholesterol, LDL cholesterol, fasting blood glucose, and HbA1c which were assessed by clinical routine methods before and after the 12-month intervention period. In addition, body weight, height, waist circumference, and resting blood pressure were determined. Physical fitness (maximal work load in watt) was assessed by bicycle ergometry with a step-wise increment in work load.

Individual data of the participants at baseline and after 12 months of intervention were documented by a standardized case report form. The study has been registered as part of a clinical trial and has been approved 
König et al.: A 12-Month Lifestyle Intervention Program Improves Body Composition and Reduces the Prevalence of Prediabetes in Obese Patients

Fig. 1. Flowchart depicting the selection process of the study population.

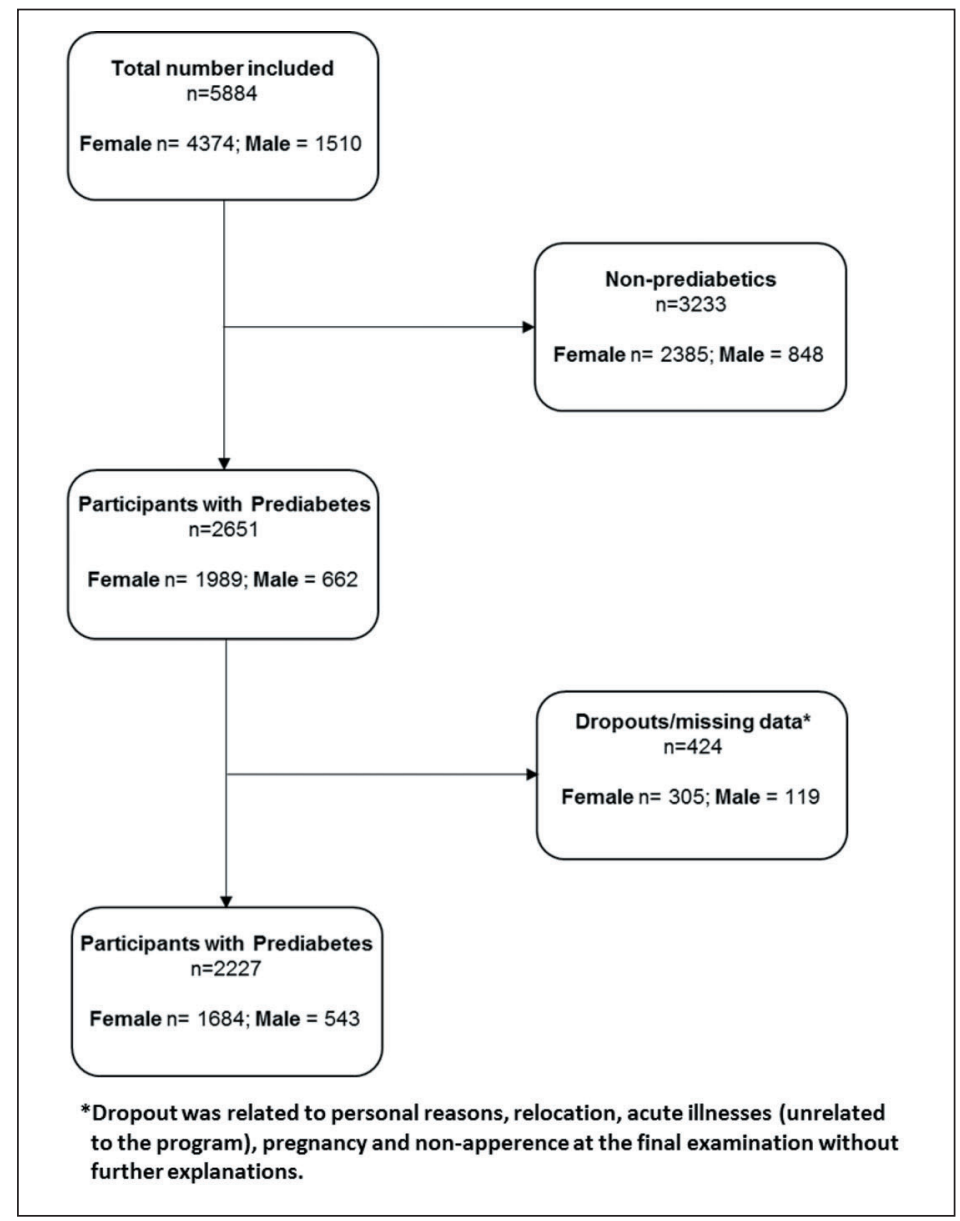

by the ethical committee of the University of Freiburg, Germany. Before entering the cohort study, all participants had to sign an informed consent for participating in the study.

Statistical analysis was performed by an independent institute (ACOMED Statistical Institute, Leipzig, Germany). Intraindividual comparison between baseline and after 12 months of intervention was assessed by the Wilcoxon test. Gender differences were assessed by the Mann-Whitney U-test.

\section{Results}

In total, 5,884 participants (age $48.6 \pm 11.3$ years) fulfilled all inclusion criteria and were included into the program. 3,233 participants had no prediabetes, and 2,651 ( $\mathrm{n}=1,989$ female, $n=662$ male) fulfilled the prediabetes criteria. Out of these prediabetics, 347 subjects dropped out during the study and 77 were excluded because of missing data at the end of the study (fig. 1). For the remaining 2,227 subjects ( $\mathrm{n}=1,684$ females; $\mathrm{n}=543$ males), data were analyzed for body weight, cardiopulmonary fitness (maximal W/kg body weight), blood pressure, and metabolic parameters (tables 1-3).

Data analysis showed that the lifestyle intervention program significantly reduced body weight $(-6 \%)$ and improved waist circumference (table 1$)$ as well as physical fitness $(+15 \%)$ in both male and female participants (table 3 ). Furthermore, all metabolic parameters as well as blood pressure and physical performance (tables 2, 3) were improved. In general, the participation rate in men was smaller; however, male participants experienced a larger 
König et al.: A 12-Month Lifestyle Intervention Program Improves Body Composition and Reduces the Prevalence of Prediabetes in Obese Patients

Table 1. Anthropometric measures of the participants (WC= waist circumference)

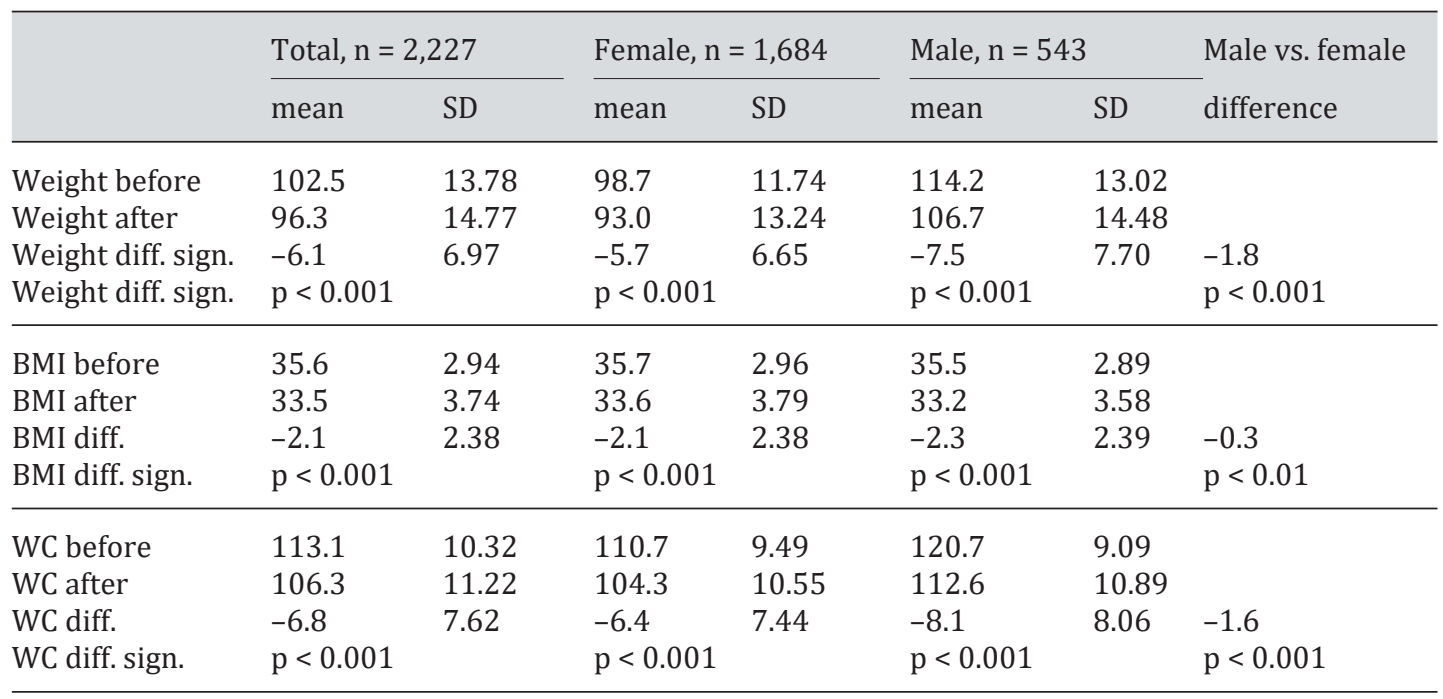

Table 2. Metabolic risk factors of the participants

\begin{tabular}{|c|c|c|c|c|c|c|c|}
\hline & \multicolumn{2}{|c|}{ Total, $\mathrm{n}=2,227$} & \multicolumn{2}{|c|}{ Female, $n=1,684$} & \multicolumn{2}{|c|}{ Male, $n=543$} & \multirow{2}{*}{$\begin{array}{l}\text { Male vs female } \\
\text { difference }\end{array}$} \\
\hline & mean & SD & mean & SD & mean & SD & \\
\hline TG before & 152.3 & 82.59 & 141.4 & 71.38 & 186.0 & 103.36 & \\
\hline TG after & 138.6 & 78.79 & 130.6 & 69.38 & 163.5 & 98.65 & \\
\hline TG diff. & -13.7 & 67.03 & -10.8 & 58.42 & -22.6 & 88.04 & -11.8 \\
\hline TG diff. sign. & \multicolumn{2}{|l|}{$\mathrm{p}<0.001$} & \multicolumn{2}{|l|}{$\mathrm{p}<0.001$} & \multicolumn{2}{|c|}{$\mathrm{p}<0.001$} & $\mathrm{p}<0.001$ \\
\hline Chol before & 218.7 & 41.14 & 220.6 & 41.78 & 212.9 & 38.54 & \\
\hline Chol after & 216.0 & 40.72 & 218.9 & 41.01 & 206.9 & 38.47 & \\
\hline Chol diff. & -2.7 & 30.30 & -1.7 & 30.39 & -6.00 & 29.81 & -4.3 \\
\hline Chol diff. sign. & \multicolumn{2}{|l|}{$\mathrm{p}<0.001$} & \multicolumn{2}{|l|}{$\mathrm{p}<0.001$} & \multicolumn{2}{|l|}{$\mathrm{p}<0.001$} & $\mathrm{p}<0.01$ \\
\hline LDL-C before & 137.1 & 35.85 & 137.7 & 36.29 & 135.2 & 34.42 & \\
\hline LDL-C after & 133.6 & 35.24 & 135.0 & 35.59 & 129.0 & 33.77 & \\
\hline LDL-C diff. & -3.6 & 25.53 & -2.7 & 25.66 & -6.2 & 24.95 & -3.5 \\
\hline LDL-C diff. sign. & \multicolumn{2}{|l|}{$\mathrm{p}<0.001$} & \multicolumn{2}{|l|}{$\mathrm{p}<0.001$} & \multicolumn{2}{|l|}{$\mathrm{p}<0.001$} & $\mathrm{p}<0.01$ \\
\hline HDL-C before & 54.7 & 13.18 & 57.6 & 12.95 & 45.9 & 9.49 & \\
\hline HDL-C after & 57.1 & 13.76 & 59.9 & 13.51 & 48.4 & 10.52 & \\
\hline HDL-C diff. & & 9.12 & 2.3 & 9.55 & 2.4 & 7.68 & 0.1 \\
\hline HDL-C diff. sign. & \multicolumn{2}{|l|}{$\mathrm{p}<0.001$} & \multicolumn{2}{|l|}{$\mathrm{p}<0.001$} & \multicolumn{2}{|l|}{$\mathrm{p}<0.001$} & n.s. \\
\hline FBS before & 98.4 & 15.30 & 97.2 & 14.72 & 102.2 & 16.40 & \\
\hline FBS after & 95.4 & 15.29 & 94.3 & 14.52 & 98.9 & 17.00 & \\
\hline FBS diff. & -3.3 & 14.32 & -3.4 & 13.54 & -3.0 & 16.45 & 0.5 \\
\hline FBS diff. sign. & \multicolumn{2}{|l|}{$\mathrm{p}<0.001$} & \multicolumn{2}{|l|}{$\mathrm{p}<0.001$} & \multicolumn{2}{|l|}{$\mathrm{p}<0.001$} & n.s. \\
\hline HbA1c before & 5.92 & 0.20 & 5.92 & 0.20 & 5.93 & 0.20 & \\
\hline HbA1c after & 5.77 & 0.34 & 5.77 & 0.33 & 5.77 & 0.39 & \\
\hline HbA1c diff. & -0.15 & 0.31 & -0.15 & 0.29 & -0.16 & 0.36 & -0.01 \\
\hline HbA1c diff. sign. & \multicolumn{2}{|l|}{$\mathrm{p}<0.001$} & \multicolumn{2}{|l|}{$\mathrm{p}<0.001$} & \multicolumn{2}{|l|}{$\mathrm{p}<0.001$} & n.s. \\
\hline
\end{tabular}

$\mathrm{TG}=$ Triglycerides; Chol = total cholesterol; LDL-C = LDL-cholesterol; HDL-C = HDL-cholesterol; FBS = fasting blood sugar; n.s. = not significant. 
König et al.: A 12-Month Lifestyle Intervention Program Improves Body Composition and Reduces the Prevalence of Prediabetes in Obese Patients

Table 3. Blood pressure and physical performance of the participants

\begin{tabular}{|c|c|c|c|c|c|c|c|}
\hline & \multicolumn{2}{|c|}{ Total, $\mathrm{n}=2,227$} & \multicolumn{2}{|c|}{ Female, $n=1,684$} & \multicolumn{2}{|c|}{ Male, $n=543$} & \multirow{2}{*}{$\begin{array}{l}\text { Male vs female } \\
\text { difference }\end{array}$} \\
\hline & mean & SD & mean & SD & mean & SD & \\
\hline BPsys before & 133.3 & 16.75 & 132.7 & 16.87 & 135.1 & 16.24 & \\
\hline BPsys after & 129.0 & 16.60 & 128.1 & 16.16 & 131.7 & 17.61 & \\
\hline BPsys diff. & -4.3 & 18.09 & -4.6 & 17.89 & -3.5 & 18.67 & 1.1 \\
\hline BPsys diff. sign. & \multicolumn{2}{|l|}{$\mathrm{p}<0.001$} & \multicolumn{2}{|c|}{$\mathrm{p}<0.001$} & \multicolumn{2}{|c|}{$\mathrm{p}<0.001$} & n.s. \\
\hline BPdia before & 85.1 & 9.70 & 84.0 & 9.52 & 86.0 & 10.18 & \\
\hline BPdia after & 82.4 & 9.71 & 82.00 & 9.48 & 83.9 & 10.26 & \\
\hline BPdia diff. & -2.7 & 11.08 & -2.9 & 10.96 & -2.1 & 11.41 & 0.8 \\
\hline BPdia diff. sign. & \multicolumn{2}{|l|}{$\mathrm{p}<0.001$} & \multicolumn{2}{|c|}{$\mathrm{p}<0.001$} & \multicolumn{2}{|c|}{$\mathrm{p}<0.001$} & n.s. \\
\hline Watt before & 1.30 & 0.32 & 1.28 & 0.30 & 1.38 & 0.36 & \\
\hline Watt after & 1.49 & 0.41 & 1.45 & 0.37 & 1.65 & 0.48 & \\
\hline Watt diff. & 0.19 & 0.31 & 0.17 & 0.28 & 0.27 & 0.37 & 0.10 \\
\hline Watt diff. sign. & \multicolumn{2}{|l|}{$\mathrm{p}<0.001$} & \multicolumn{2}{|c|}{$\mathrm{p}<0.001$} & \multicolumn{2}{|c|}{$\mathrm{p}<0.001$} & $\mathrm{p}<0.001$ \\
\hline
\end{tabular}

$\mathrm{BP}=$ Blood pressure; sys = systolic, dia = diastolic; Watt = performance in total watts during a bicycle ergometry with incremental work load; n.s. = not significant.

benefit in body weight and body composition as well as in serum triglycerides and LDL cholesterol (table 2).

Overall, in 839 of the 2,227 participants who were prediabetic before intervention, the criteria of prediabetes were no longer detectable and HbA1c levels normalized after intervention (-37.7\%) (fig. 2). In contrast, 66 participants converted to manifest T2DM (+2.9\%). Similarly, $766(46.7 \%)$ of the 1,641 participants fulfilling the criteria of the metabolic syndrome before the intervention, did not show any signs of this syndrome after the intervention; however, 120 participants newly developed criteria for the metabolic syndrome (+7.3\%) (fig. 2).

\section{Discussion}

The data after the 12-month intervention demonstrate the substantial and significant benefit of this standardized, multidisciplinary lifestyle modification program (M.O.B.I.L.I.S. program). To the author's knowledge, this study is of one of the largest lifestyle intervention programs in obese and prediabetic patients showing that obese persons with a BMI between 30 and $40 \mathrm{~kg} / \mathrm{m}^{2}$ can successfully lose weight, even if they are prediabetic. A mean weight reduction of about $6 \mathrm{~kg}$ has been demonstrated after 12 months, all in all in both genders and across different age groups. Considering that a spontaneous weight gain of about $0.5 \mathrm{~kg}$ within 12 months could have been expected [11], the mean weight loss of about $6 \mathrm{~kg}$ can definitely be considered as favorable.

Reversal of prediabetes to normal glucose metabolism was observed in $37.7 \%$ of the participants. These participants had shown a very good adherence (more than $80 \%$ ) to the guided lifestyle intervention sessions. Data from the DPP have suggested that those patients, who converted to normal glucose regulation within the intervention period, subsequently experienced a significantly lower chance of developing T2DM during the 6-year follow-up. It is likely that these metabolic benefits will eventually not only yield to a lower incidence of T2DM but will also reduce cardiovascular events in these high-risk patients [12]. 
Fig. 2. Number of participants with prediabetes as well as metabolic syndrome before and after the intervention.
König et al.: A 12-Month Lifestyle Intervention Program Improves Body Composition and Reduces the Prevalence of Prediabetes in Obese Patients

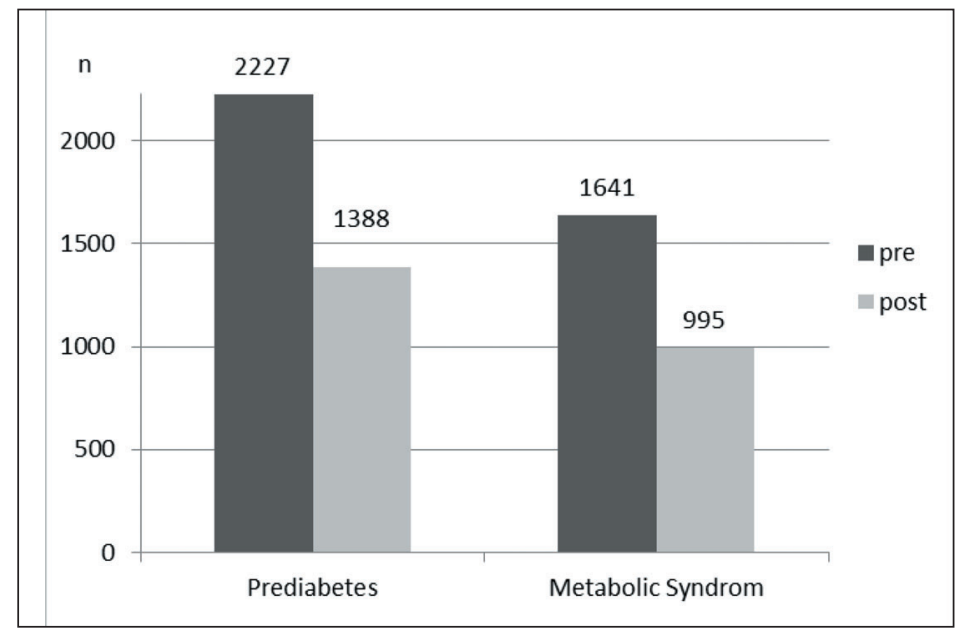

Of course, there were significant differences between men and women with respect to absolute weight and waist circumference as expected from gender-specific anthropometric differences in body composition. However, there were only small differences in BMI changes between female and male participants. Therefore, it can be assumed for both groups that the mean reduction in waist circumference of about $7 \mathrm{~cm}$ corresponds to a favorable reduction in visceral fat mass of about $2 \mathrm{~kg}$ [13]. This result, which is in agreement with improvements of the criteria of the metabolic syndrome, may also reflect an important reduction in the overall cardiovascular risk. This, however, needs to be proven in forthcoming studies.

An exact evaluation of muscle mass is not feasible in routine clinical practice. Therefore, no parameters other than BMI and waist circumference were recorded to assess body composition. Thus, the exact component, i.e. fat or muscle mass, that has been reduced by the intervention could not be determined. Nevertheless, the final examination showed that the relative performance $(\mathrm{W} / \mathrm{kg}$ body weight $+15 \%)$ increased to a higher extent than expected from weight loss (-6\%). Therefore, although the evidence is rather hypothetical, this result may be interpreted by a rather favorable improvement in body composition and an increase in the ratio of fat mass to muscle mass as well as in muscle function. However, the relative proportion of functional versus structural improvement in muscular function remains to be determined.

Nevertheless, this health care research study has limitations due to the lack of a randomized design. However, this approach is important as it reflects real-life condition in today's health care system. Nonetheless, the positive effects are limited to an intervention arm only and include only participants generally supporting lifestyle interventions. However, our overall results are clinically significant and certainly support the role of lifestyle interventions in obese subjects with metabolic syndrome, particularly in those who are at risk for developing T2DM.

\section{Conclusion}

The results from this multicenter cohort study have shown that the applied intense and multidisciplinary lifestyle interventions were successful, even in obese subjects with prediabetes. From the 2,227 participants who were initially prediabetic, 839 participants $(-37.7 \%)$ did no longer show the criteria of prediabetes after the intervention and had normal HbA1c levels. The clinical effects are substantial and are likely to reduce the risk of developing 
König et al.: A 12-Month Lifestyle Intervention Program Improves Body Composition and Reduces the Prevalence of Prediabetes in Obese Patients

diabetes and the prevalence of a full-blown metabolic syndrome in obese and prediabetic patients. Important criteria for a successful intervention seem to be a standardized program, central coordination, and financial coverage by the patient's health insurance company.

\section{Disclosure Statement}

The authors König D., Hörmannn J., Predel H-G., and Berg A. declare that they have no conflict of interest.

\section{References}

1 Field AE, Coakley EH, Must A, Spadano JL, Laird N, Dietz WH, Rimm E, Colditz GA: Impact of overweight on the risk of developing common chronic diseases during a 10-year period. Arch Intern Med 2001;161:1581-1586.

-2 Diabetes Prevention Program Research Group, Knowler WC, Fowler SE, Hamman RF, Christophi CA, Hoffman HJ, Brenneman AT, Brown-Friday JO, Goldberg R, Venditti E, Nathan DM: 10-year follow-up of diabetes incidence and weight loss in the Diabetes Prevention Program Outcomes Study. Lancet 2009;374:1677-1686.

-3 Tuomilehto J, Lindström J, Eriksson JG, Valle TT, Hämäläinen H, Ilanne-Parikka P, Keinänen-Kiukaanniemi S, Laakso M, Louheranta A, Rastas M, Salminen V, Uusitupa M; Finnish Diabetes Prevention Study Group: Prevention of type 2 diabetes mellitus by changes in lifestyle among subjects with impaired glucose tolerance. N Engl J Med 2001;344:1343-1350.

-4 Perreault L, Pan Q, Mather KJ, Watson KE, Hamman RF, Kahn SE: Effect of regression from prediabetes to normal glucose regulation on long-term reduction in diabetes risk: results from the Diabetes Prevention Program Outcomes Study. Lancet 2012;379:2243-2251.

5 Authors/Task Force Members, Piepoli MF, Hoes AW, Agewall S, Albus C, Brotons C, Catapano AL, Cooney MT, Corrà U, Cosyns B, Deaton C, Graham I, Hall MS, Hobbs FD, Løchen ML, Löllgen H, Marques-Vidal P, Perk J, Prescott E, Redon J, Richter DJ, Sattar N, Smulders Y, Tiberi M, van der Worp HB, van Dis I, Verschuren WM; Additional Contributor: Simone Binno (Italy); Document Reviewers:, De Backer G, Roffi M, Aboyans V, Bachl N, Bueno H, Carerj S, Cho L, Cox J, De Sutter J, Egidi G, Fisher M, Fitzsimons D, Franco OH, Guenoun M, Jennings C, Jug B, Kirchhof P, Kotseva K, Lip GY, Mach F, Mancia G, Bermudo FM, Mezzani A, Niessner A, Ponikowski P, Rauch B, Rydén L, Stauder A, Turc G, Wiklund O, Windecker S, Zamorano JL. 2016 European Guidelines on cardiovascular disease prevention in clinical practice: The Sixth Joint Task Force of the European Society of Cardiology and Other Societies on Cardiovascular Disease Prevention in Clinical Practice (constituted by representatives of 10 societies and by invited experts): developed with the special contribution of the European Association for Cardiovascular Prevention \& Rehabilitation (EACPR). Eur J Prev Cardiol 2016; 23:Np1-Np96.

-6 Barry E, Roberts S, Oke J, Vijayaraghavan S, Normansell R, Greenhalgh T: Efficacy and effectiveness of screen and treat policies in prevention of type 2 diabetes: systematic review and meta-analysis of screening tests and interventions. BMJ 2017;356:i6538.

7 Lagerstrøm D, Berg A Jr, Haas U, Hamm M, Göhner W, Fuchs R, Predel HG, Berg A: Das M.O.B.I.L.I.S.-Schulungsprogramm. Bewegungstherapie und Lebensstilintervention bei Adipositas und Diabetes. Diabetes aktuell 2013;11:5-11.

8 Berg A Jr, Frey I, Hamm M, Göhner W, Berg A. Das M.O.B.I.L.I.S.-Programm Erfolgreiche ambulante Therapie auch für Typ-2-Diabetiker. Diabetologe 2011;3:1-3.

9 Berg A, Berg A, Frey I, Konig D, Predel HG: Exercise based lifestyle intervention in obese adults: results of the intervention study M.O.B.I.L.I.S. Dtsch Arztebl Int 2008;105:197-203.

10 Göhner W, Schlatterer M, Seelig H, Frey I, Berg A Jr, Fuchs R: Two-year follow-up of an interdisciplinary cognitive-behavioral intervention program for obese adults. J Psychol 2012;146:371-391.

-11 Drøyvold WB, Nilsen TI, Krüger O, Holmen TL, Krokstad S, Midthjell K, Holmen J: Change in height, weight and body mass index: longitudinal data from the HUNT Study in Norway. Int J Obes (Lond) 2006;30:935-939.

-12 Tabák AG, Herder C, Rathmann W, Brunner EJ, Kivimäki M: Prediabetes: a high-risk state for diabetes development. Lancet 2012;379:2279-2290.

13 Ross R, Dagnone D, Jones PJ, Smith H, Paddags A, Hudson R, Janssen I: Reduction in obesity and related comorbid conditions after diet-induced weight loss or exercise-induced weight loss in men. A randomized, controlled trial. Ann Intern Med 2000;133:92-103. 